\title{
Comments Are More Important Than Code
}

Jef Raskin, Independent Consultant

l $\mathrm{n}$ this essay I take what might seem a paradoxical position. I endorse the techniques that some programmers claim make code self-documenting and encourage the development of programs that do "automatic documentation." Yet I also contend that these methods cannot provide the documentation necessary for reliable and maintainable code. They are only a rough aid, and even then help with only one or two aspects of documentation-not including the most important ones.

Enforcing excellence in documentation of code is on the frontier of unsolved problems in the management of software development. Some of the solutions seem effective, but they are not yet in the culture of programming or programming education. Rare is the programming teacher who will downgrade a properly performing program because of inadequate documentation.

I discard the radical position taken by proponents of extreme programming (XP) to get rid of "unnecessary" documentation. To some programmers, asking for any documentation is seen as an impediment to getting the "real work" done. XP in general is nicely skewered by Matt Stephens and Doug Rosenberg in Extreme Programming Refactored: The Case Against XP (Apress, 2003).

When programmers speak of "self-documenting code," they mean that you should use techniques such as clear and understandable variable names. Instead of $\mathrm{n}$ or count, it is better to use a readable, self-explanatory name such as numberOfApricotsPickedToDate. This is a minimalist's documentation. Nonetheless, it helps-the use of explanatory names, whether of variables, modules, objects, or programs, should be encouraged.

In-line comments are problematical, often useless:

$\mathrm{t}(\mathrm{i})<=\mathrm{t}(\mathrm{i})+13 \quad /{ }^{*}$ Add 13 to the ith element of $\mathrm{t} *$

But their real problem is their forced brevity. The impulse to toss off a comment quickly is enhanced when the language syntax forces the programmer to be curt: such comments are confined to a portion of one line. When indentation is deep, it can be a small portion indeed:

blix.VK(tofu.haha.cogau) \& 00110011B /* mask */

\section{The thorough use of}

INTERNAL DOCUMENTATION

IS ONE OF THE MOST-

OVERLOOKED WAYS OF

IMPROVING SOFTWARE

QUALITY AND SPEEDING

IMPLEMENTATION.

Many become so laconic that you have to understand the code to be able to interpret the comment. Such comments often get further truncated or lost altogether as the program continues to be written or is updated. They are, therefore, also a maintenance headache.

I do not use in-line comments, and I discourage their use by programmers who work with me. If you are going to write a comment, give yourself at least a full line. Or, better yet, give yourself as much space as you need. Some development environments confine comments to a single line. If you wish to make a multiline comment, you have to represent it as a set of single lines. This means that there is no word wrap-to say nothing of many other features that the simplest note-taking software provides. You want to change the comment? You will have to adjust all the line lengths by hand. This is punitive, discourages documentation, and should go where GOTOs went.

Any language or system that does not allow full flowing and arbitrarily long comments is seriously behind the times. That we use escape characters to "escape" from code to comment is backwards. Ideally, comment should be the default, with a way to signal the occasional lines of code.

Automatic documentation generators create flow charts, inheritance diagrams, tables of contents, indexes, topic lists, cross-references, and context-sensitive help entries. One advertised itself as being able "to automatically and continuously update all aspects of the source code documentation, so that the entire team has all the necessary information at their fingertips. Using the information stored in the dictionary and the source files [it] can automatically generate source code documentation."

The obvious problem is that they do it quite badly. As anybody who has done good documentation knows, generating even an index is not a straightforward, automatic task. The less obvious problem is that many coders feel Continued on page 62 


\section{Continued from page 64}

that once they've run the documentation builder over their code, they have documented it. This is the same as the common syndrome of assuming that a document is spelled correctly once the spelling checker no longer flags any words. If you get such "documentation" with a program and find it far from adequate, remember that "eye tolled ewe sew."

But the fundamental reason code cannot ever be selfdocumenting and automatic documentation generators can't create what is needed is that they can't explain why the program is being written, and the rationale for choosing this or that method. They cannot discuss the reasons certain alternative approaches were taken. For example:

:Comment: A binary search turned out to be slower than the Boyer-Moore algorithm for the data sets of interest, thus we have used the more complex, but faster method even though this problem does not at first seem amenable to a string search technique. :End Comment:

This comment not only names the technique used, but also explains why a simpler approach was not taken.

Good documentation should be readable on its own, with bits of code showing how the design is implemented (and making it run, of course). Reconstructing code from good documentation is far easier than trying to create documentation given the code. Indeed, it is impossible to take code and create the documentation that should have been written as the code was being developed.

Donald Knuth's work is gospel (except for his writing on religion) for all serious programmers. His essay "Literate Programming" (Computer Journal, May 1984; reprinted

\section{Comment should be the}

\section{default, with a way to signal the}

\section{occasional lines of code.}

in Knuth, D. CSLI Lecture Notes 27: Literate Programming, Stanford, 1992) is must reading. I do not think we need all of his mechanism, but the essential concept of writing the documentation first, creating the methods in natural language, and describing the thinking behind them is a key to high-quality commercial programming. I emphasize commercial because we all know the high cost of customer dissatisfaction and the even higher cost of handling avoidable customer calls. The use of internal documentation is one of the most-overlooked ways of 
improving software and speeding implementation.

An example of the kind of documentation I speak of appears as part of an interview I did for Susan Lammers's Programmers at Work: Interviews (Microsoft Press, 1986). The caption reads, "This program demonstrates how Raskin embeds executable code into text that is produced by a word processor." It is also an example of using an escape method for the code instead of the comments.

It is important not to be doctrinaire about this. I can imagine a programming manager reading this and Knuth, and saying "The answer to my problems!" and mandating that all work be done this way. As Frederick Brooks tells us in The Mythical Man-Month (Addison Wesley, 1995), "There is no silver bullet." A competent programmer who has learned the documentation-first style will sometimes think of a solution in terms of code, write that first, and then document, or will apply a mixed strategy—especially when no convoluted algorithm design is involved. This should not be discouraged so long as the programmer generally adheres to (and sincerely supports) the documentation-first approach.

Do not believe any programmer, manager, or salesperson who claims that code can be self-documenting or automatically documented. It ain't so. Good documentation includes background and decision information that cannot be derived from the code. It is hard to imagine any foreseeable software or robot that could collect this information from the people involved with a programming project - at the very least it must understand natural language, which is still the Holy Grail to the AI community.

Prior, clear, and extensive documentation is a key element in creating software that can survive and adapt. Documenting to high standards will decrease development time, result in better work, and improve the bottom line. It's hard to ask for more than that from any technique. $Q$

\section{LOVE IT, HATE IT? LET US KNOW}

feedback@acmqueue.com or www.acmqueue.com/forums

\section{JEF RASKIN, professor of computer science at the University} of Chicago, is best known for his book, The Humane Interface (Addison-Wesley, 2000), and for having created the Macintosh project at Apple. He holds many interface patents, consults for companies around the world, and is often called upon as a speaker at conferences, seminars, and universities. His current project, The Humane Environment (http:// humane.sourceforge.net/home/index.html), is attracting interest in both the computer science and business worlds. (c) 2005 ACM 1542-7730/05/0300 $\$ 5.00$
The University of Arkansas at Little Rock (UALR) invites application for the position of Chair of the Department of Computer Science. The position will begin on July 1, 2005.

The department chair is a member of the department faculty and serves a term of three years, with the possibility of renewal. The department chair provides leadership in accomplishing the department's mission, encouraging an environment of collegiality and consultation, presides at meetings of the department, supervises support staff, serves as the channel of official communication between the department faculty and the administration, and represents the department on and off campus. The department chair is also responsible for managing the department's budget, managing department resources, developing class schedules, and assigning teaching responsibilities.

The Computer Science Department offers an ABET/CAC-accredited B.S degree in Computer Science, an M.S. in Computer Science, and its faculty members serve as dissertation advisors for the Ph.D. in Applied Science with an emphasis in either Applied Computing or Computational Science offered through the graduate Department of Applied Science at UALR. There are currently ten full-time faculty members, one laboratory manager, and an administrative secretary.

The Department is a part of the Donaghey College of Information Science and Systems Engineering (Cyber College). The College offers several degree programs through its departments of Applied Science, Construction Management, Computer Science, Engineering Technology, Information Science, and Systems Engineering. These programs afford ample opportunity for grant and consulting work with several information technology companies and government agencies in the Little Rock area.

UALR is a comprehensive urban university serving a diverse student body of approximately 12,000 students. It is the second largest university in the University of Arkansas System, and is located on a beautiful 150-acre campus a few miles from downtown Little Rock. Little Rock, the geographic, economic, demographic, and political center of the state, is a pleasant cosmopolitan city of 175,000 , and affords ample cultural and recreational opportunities year-round. It is a short drive from some of the most scenic areas to be found anywhere. Little Rock is also the home of Fortune 500 knowledge-based companies such as Acxiom and Alltel. This creates opportunities for faculty members to engage in research and consulting activities with these firms. It has a thriving art, music, and theater scene. Outdoor and recreational activities abound in the nearby Ouachita and Ozark National Forest, Buffalo National River, Hot Springs National Park, and many other locations of interest.

Qualifications: Candidates must have

- an earned doctorate in Computer Science

- an outstanding record of accomplishments in teaching, funded research, and public service to qualify for the rank of associate professor or professor with the possibility of tenure

- demonstrated strong leadership

- detailed knowledge of assessment and accreditation issues

Please send cover letter, vitae and at least three letters of recommendation to Search Committee

Department of Computer Science

University of Arkansas at Little Rock

2801 South University Avenue

Little Rock, AR 72204-1099

Phone: (501) 569-8130

Email: csdept@ualr.edu

Review of applications will begin immediately and will continue until the position is filled. The University of Arkansas at Little Rock is an equal opportunity, affirmative action employer and actively seeks the candidacy of minorities, women and persons with disabilities. Under Arkansas law, all applications are subject to disclosure. Persons hired must have proof of legal authority to work in the United States. 